\title{
Soot and smoke emissions numerical evaluation for a direct injection (DI) diesel engine
}

\author{
Bogdan $\mathrm{Radu}^{1}$, Alexandru Racovitza ${ }^{1, *}$, and Radu Chiriac $^{1}$ \\ ${ }^{1}$ University POLITEHNICA Bucharest Dept. of Thermodynamics, Engines, Thermal and Refrigerant \\ Systems, Romania
}

\begin{abstract}
The reduction of Diesel internal combustion engines emissions is one of the major concerns of the engines manufacturers. Despite the fact that the efficiency of the gas post-treatment systems has been significantly improved, decreasing the smoke and the soot from the cylinder inside remains a main research goal. This work is proposing a theoretical study on these pollutants formation for different kinds of direct injection methods. By dividing the in-cylinder injection the heat release characteristic could be modified, leading to different temperature and pressure levels. Using exhaust gas recirculation (EGR) the reduction of the gas temperatures might also be decreased, limiting $\mathrm{NO}_{\mathrm{x}}$ formation. To evaluate the level of the cylinder gas emissions formation a two-step procedure could be followed. First, by using a numerical calculation system the heat release characteristic can be highlighted concerning a Diesel engine with stratified injection; then, using an experimental relationship applying a large data base, the amount of the gas emissions can be subsequently provided. The authors propose some combinations between injection characteristics and EGR used fractions which could generate successfully results speaking in terms of $\mathrm{NO}_{\mathrm{x}}$, soot and smoke formation.
\end{abstract}

\section{Introduction}

The greatest concern referring to the use of commercial Diesel engines is to identify reasonable and applicable solutions in order to fit the limitations regarding the exhaust emissions. Therefore, the control of NOx, smoke and particulate matter concentrations is the basic target among the general activity of developing Diesel engines in terms of increasing their performance and efficiency.

Simulation and experimental research have proposed different techniques in order to cover the processes development inside the cylinder, from which air-fuel mixture formation, combustion and heat release play crucial role in the control of the motor fluid thermal status and consequently of the NOx genesis and exhaust. Thus, solutions like split

*Corresponding author: alexandru racovitza@yahoo.com 
injection and injection timing adjustment [1], premixed combustion [2], injector and nozzle geometric modifications [3], water or further more combinations of hydro-oxygenated fuels injection have been studied [4-7]. Separately or together with these, the Exhaust Gas Recirculation (EGR) method allows as well the reduction of the heat peak temperature reached inside the cylinder [8-9].

The more drastic limitations stipulated by the recent Euro 6 stages standards impose continuously reducing of Diesel engines emissions. Moreover, commercial vehicles with direct injection engines are limited at $0.005 \mathrm{~g} / \mathrm{km}$ for Euro 5 and Euro 6. Starting with Euro $5 \mathrm{~b}$ a particulate number standard (PN) has been established in 2011 for diesel engines, valued at $6 \times 10^{11}$ per $\mathrm{km}$ and it was assigned also for gasoline engines in 2014 with Euro 6 [10-11].

The emissions formation has been subjected for simulation development studies more than three decades, since soft packages occurred as valuable theoretical research tools. Computational Fluid Dynamics (CFD) is also used for numerical analysis using data structures to better describe and solve problems linked to the engine fluid dynamics [1213]. The obtained results presented in this paper are based on the AMESIM [14] numerical code, used in order to establish the necessary link between model result and the predictive experimental results of the engine.

\section{Modeling the engine processes}

In order to obtain the engine operating parameters as a result of diesel fuel injection variables when using a direct injection diesel engine, a specialized program AMESIM has been used [14]. This allows the creation of a diesel engine model with a multiple stage split injection (see Figure.1).

\section{Single Cylinder turbocharged diesel engine}
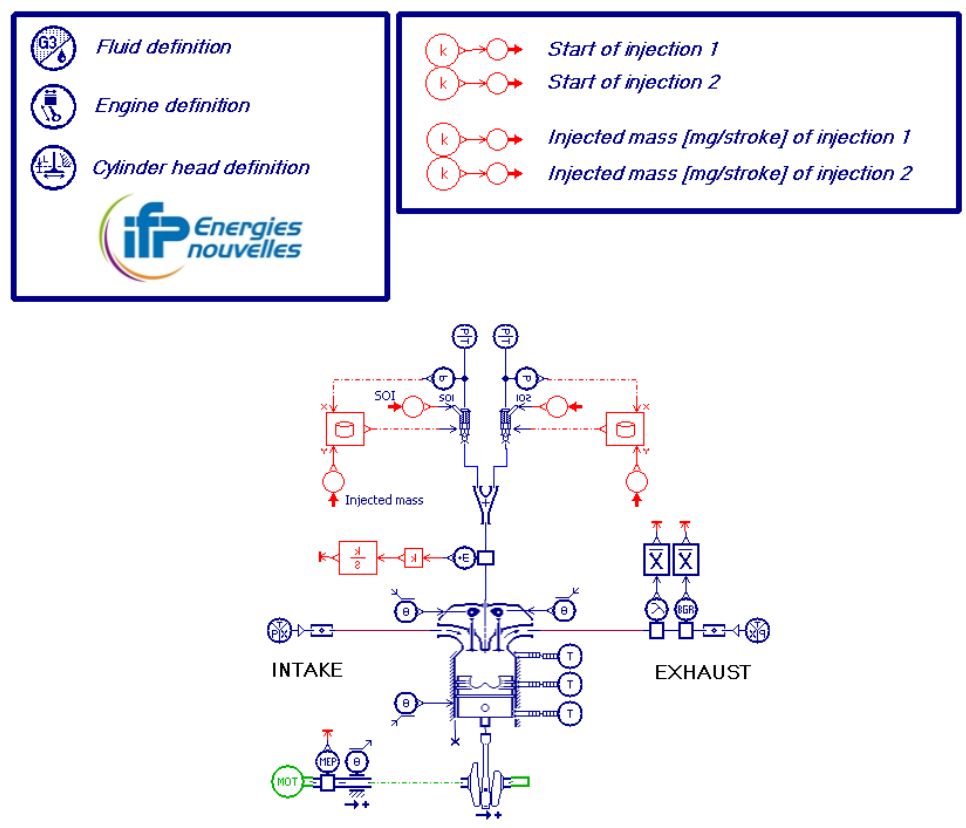

Fig. 1. Model of the single cylinder Diesel engine. 
In order to simplify the engine model only one of the engine cylinders has been schematized. Regarding the gas exchange both inlet and exhaust are isobar processes. The structure elements defining the gas exchange systems are consisting parts of the IFP Engine Library [14] and allow the options for the engine operating parameters.

The main component of the system is the Diesel engine cylinder (see Fig.2) and contains 9 ports for the input and the output data transfer [15].

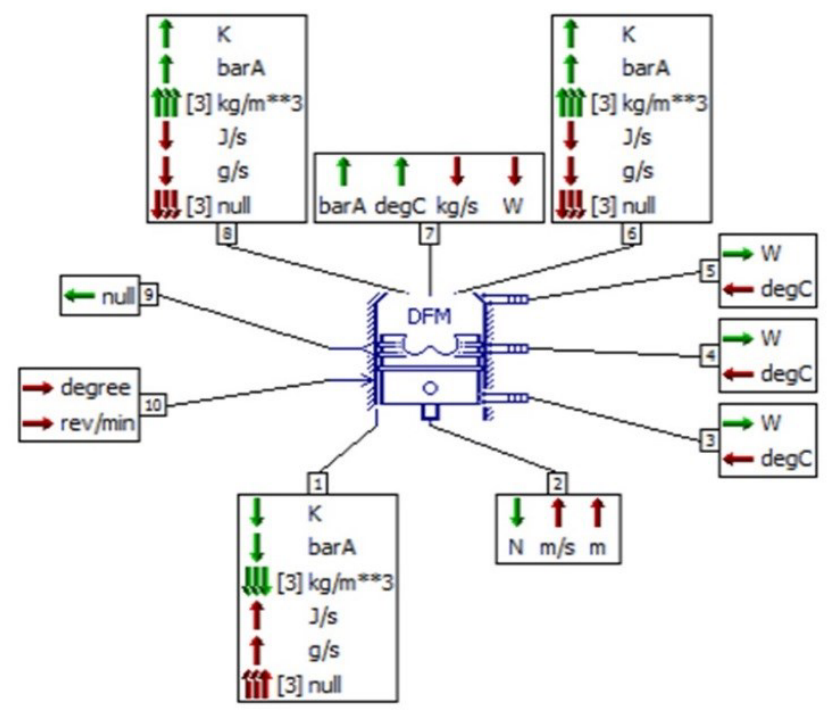

Fig. 2. The Diesel engine cylinder model

The combustion phase is using a model based on a previous work [16]. This considers a two stage scenario for the fuel burning process: the combustion of the preformed mixtures and the diffusive combustion. A first fuel injected mass covers in time the autoignition delay and the rest of the injected fuel is presumed to ignite immediately. For the autoignition delay time period the following Arrhenius type formula could be use:

$$
\tau_{i}=\left(1+10 \times X_{\mathrm{BGR}}\right) A_{t} \times p^{-n} \times e^{\left(\frac{T a}{T}\right)}
$$

in which the only difference comparing to the classic form is the insert of $\mathrm{X}_{\mathrm{BGR}}$ that defines the molar concentration of the burned gas before combustion and marks the effect of the exhaust recirculated gas accumulated together with the burned gas until the start of injection. Each unit of fuel injected mass should have its own description in terms of heat release.

The scenario of the preformed air-fuel mixtures formation could be expressed by five phenomena [15]:

1. The fuel is injected and vaporizes.

2. A mixing zone is formed, where the air is motioned into the fuel spray.

3. The preformed mixtures continue to form until the end of the autoignition period.

4. After this period the mixtures ignite, leading to the flame propagation through the reactive environment.

5. The combustion is reaching the cylinder volume.

In the case of split injection this scenario is repeating after each injected unit. Referring to those units injected after the combustion start the in-cylinder parameters are strongly affected, causing a significant reduction of the autoignition delay. Thus, for these following 
injection sequences the preformed mixtures should have a less important influence.

This above presented model [16] has been implemented in AMESIM.

\section{The modeling results}

In order to evaluate the engine performance a commercial Renault Energy dCi Diesel engine has been chosen as basic model. Its features are: $30 \mathrm{~kW} /$ cylinder rating power at $3500 \mathrm{rpm}, 85 \mathrm{~mm}$ bore and $102 \mathrm{~mm}$ stroke. Its turbocharging pressure is $0.18 \mathrm{MPa}$, compression ratio 16 and for the chosen operating regime the relative air-fuel ratio is 1.42 . At the beginning of the study the injection was considered an undivided process.

The optimized injection advance for to this regime is $18 \mathrm{deg}$ CA (Crankshaft Angle degrees), corresponding to a power of $30.3 \mathrm{~kW}$. The pressure diagram and the temperature on cycle variation are highlighted in Figure 3. The peak firing pressure is $15.8 \mathrm{MPa}$ and the maximum temperature is $2450 \mathrm{~K}$.

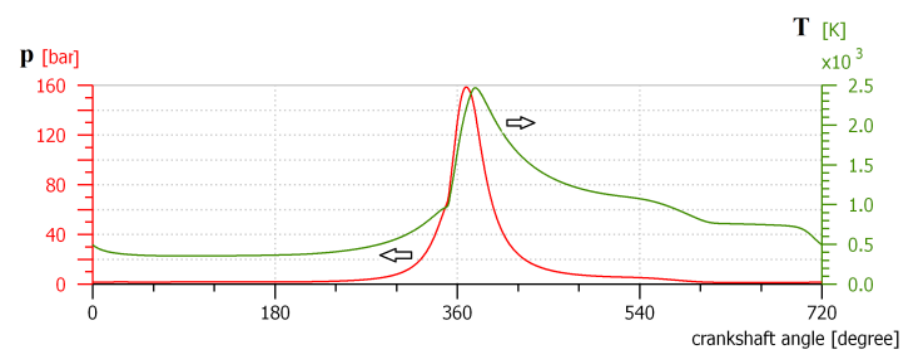

Fig. 3. Basic cycle pressure and temperature variations

The optimal situation has been chosen corresponding to the maximal values of the efficiency or of the rated power, as seen in Figure 4. This shows the fact that the $1 \%$ increase of the power is related to an increase of the cycle peak firing pressure from 13 $\mathrm{MPa}$ to $15.8 \mathrm{MPa}$, therefore the nitrogen oxides will significantly increase.

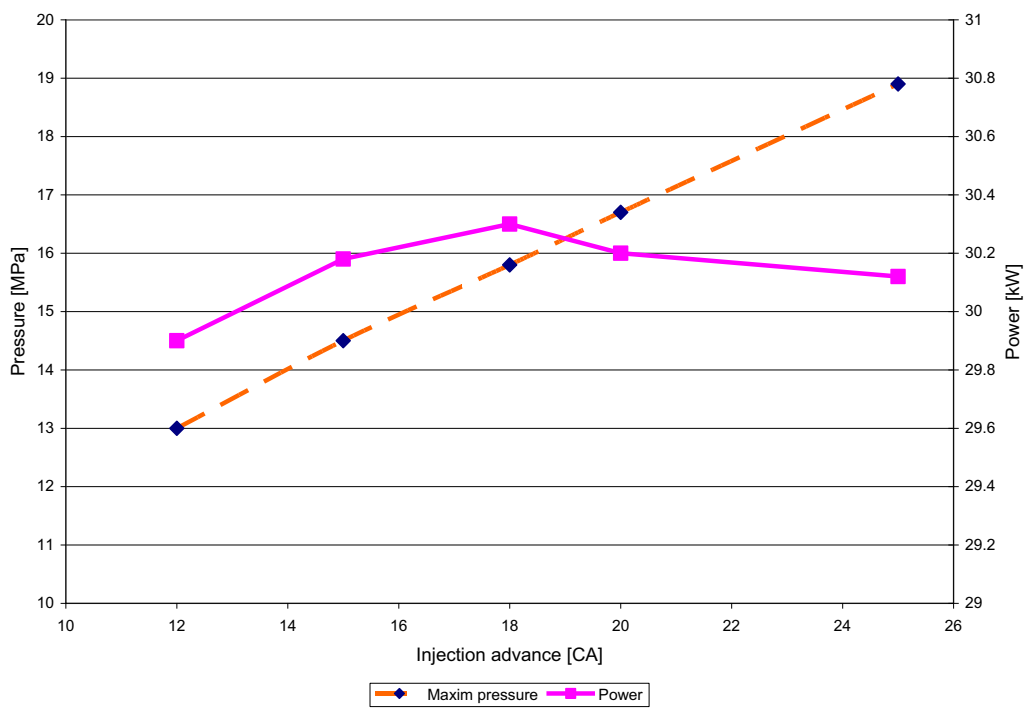

Fig. 4. Identifying the optimal injection advance value 
From the point of view of the combustion development, for this situation characterized by $120 \mathrm{MPa}$ fuel injection pressure the start of injection is at $342 \mathrm{deg}$ and the end of the autoignition delay is at $348.8 \mathrm{deg}$. It can be also added that $5 \%$ of the fuel mass burning corresponds to $352.7 \mathrm{deg}$, its $50 \%$ fraction corresponds to $365.4 \mathrm{deg}$ and $90 \%$ fraction corresponds to $377.6 \mathrm{deg}$. The end of combustion is marked at $397 \mathrm{deg}$.

\section{$4 \mathrm{NO}_{x}$ and soot emissions calculation}

The theoretical calculation of nitrogen oxides and soot formation is a far complicated issue, due not only to their genesis mechanism, largely known, but mostly because to the fact that these reactions occur in very special zones of the combustion chamber. Because of that these calculations can not be performed using phenomenological models which consider only the global conditions existing inside the combustion chamber.

There are two empirical formulas [16] based on a large number of experiments in order to evaluate the two type emissions as a function of the cylinder conditions and the pressure diagram characteristics.

$$
\begin{gathered}
\text { Soot(filter smoke number) }=K_{1} \times Z V^{e 1} \times \propto_{1}^{e 2} \times\left(\frac{d p}{d \emptyset}\right)_{\text {max }}^{e 3} \times \propto_{2}^{e 4} \times O_{2}^{e 5} \times\left(\frac{m_{\text {Luft }}}{m_{\text {gesamt }}}\right)^{e 6} \\
\operatorname{NOx}(\mathrm{ppm})=K_{2} \times Z V^{f 1} \times \propto_{1}^{f 2} \times\left(\frac{d p}{d \emptyset}\right)_{\text {max }}^{f 3} \times \propto_{2}^{f 4} \times O_{2}^{f 5} \times\left(\frac{m_{\text {Luft }}}{m_{\text {gesamt }}}\right)^{f 6}
\end{gathered}
$$

In these expressions, the symbols have the following meaning:

- $\mathrm{K}_{1}, \mathrm{~K}_{2}$ are the proportionality coefficients, each for each emission type;

- ZV is the autoignition delay;

$-\alpha_{1}$ is the angle formed with the horizontal axis by the line between the combustion starting point and the highest point of the heat release characteristic;

- $\alpha_{2}$ is the angle formed with the horizontal axis by the line between the combustion ending point and the highest point of the heat release characteristic (see Figure 5);

- $(\mathrm{dp} / \mathrm{d} \varphi)$ max is the maximum rate of the pressure increase, peaked from the pressure diagram;

- $\mathrm{O}_{2}$ is the oxygen concentration from the exhaust gas;

- $\left(\mathrm{m}_{\text {air }} / \mathrm{m}_{\text {fresh charge }}\right)$ is the ratio between the air quantity and the entire fresh charge;

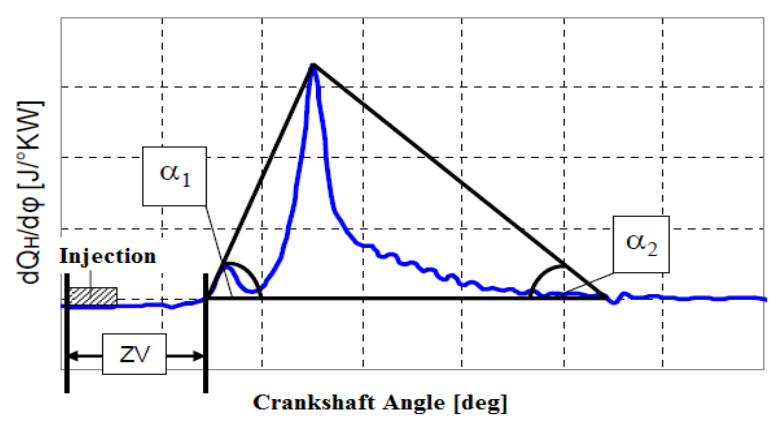

Fig. 5. The evaluation of $\alpha_{1}$ and $\alpha_{2}$ angles

Each of the above terms have an exponent (symbolized from a to f) and an index (from 
1 to 6) numerically established to offer a good correlation with the experimental data. These 7 used terms [16] are listed in Table 1:

Table 1 Equation's 2 and 3 constant values

\begin{tabular}{|l|c|c|c|c|c|c|c|}
\hline & $\mathrm{K}$ & 1 & 2 & 3 & 4 & 5 & 6 \\
\hline Soot & 1.74 & -0.93 & 1.93 & -0.06 & -1.86 & -1.37 & -0.25 \\
\hline $\mathrm{NO}_{\mathrm{x}}$ & 177.3 & 0.19 & 1.67 & 0.86 & -1.92 & 0.45 & 2.98 \\
\hline
\end{tabular}

As a remark of the different sign referring to the terms 5 and 6 , those depending on the cylinder air-fuel ratio, it means that decreasing one of them the other one increases.

\section{Emissions evaluation at split injection}

The evaluation for the emissions regarding the engine basic operating regime starts with the evaluation of the pressure diagram and the evaluation of the heat release characteristic (see Fig. 6).

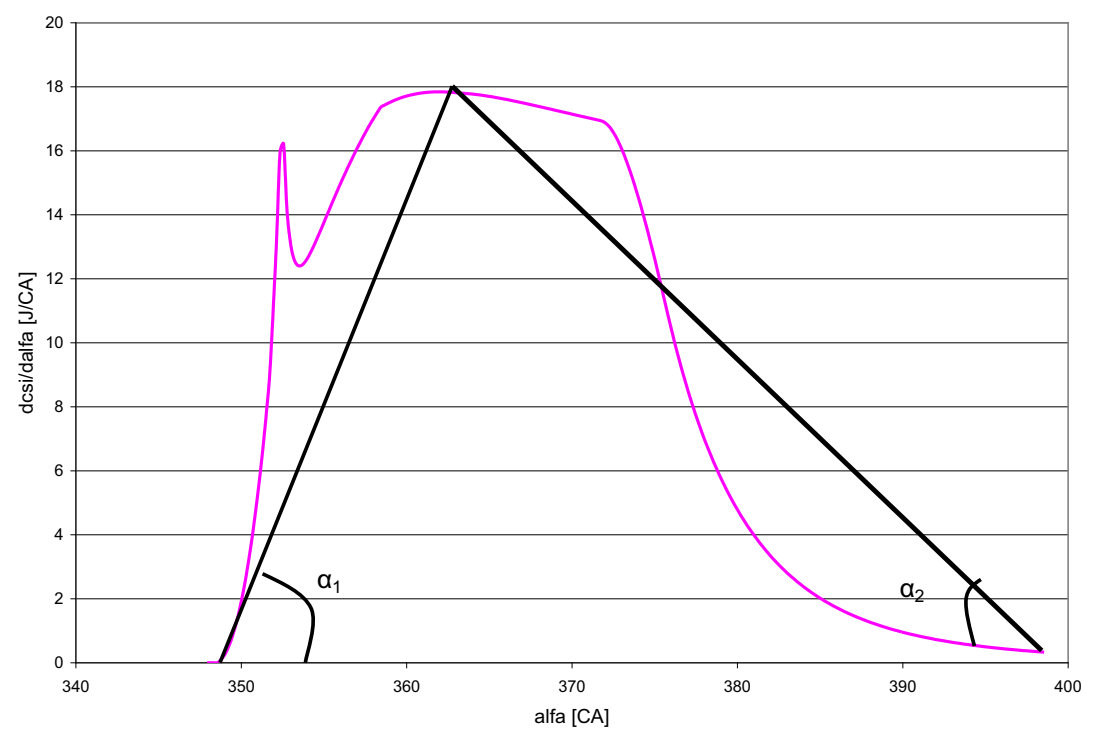

Fig. 6. Rate of heat release $[\mathrm{J} / \mathrm{CA}]$

The maximum rate of the pressure increase is $8.48 \mathrm{bar} / \mathrm{deg} \mathrm{CA}$, the autoignition delay is about $7 \mathrm{deg} \mathrm{CA}$ and the injection phase period is $48 \mathrm{deg} \mathrm{CA}$. The terms used in the emissions calculation formula are (listed in Table 2):

Table 2 Equation's 2 and 3 values for basic regime

\begin{tabular}{|c|c|c|c|c|c|c|c|}
\hline $\mathrm{ZV}$ & $\alpha_{1}$ & $(\mathrm{dp} / \mathrm{d} \varphi)_{\max }$ & $\alpha_{2}$ & $\mathrm{O}_{2}$ & $\mathrm{~m}_{\text {air }} / \mathrm{m}_{\text {fresh charge }}$ & $\mathrm{NO}_{\mathrm{x}}$ & Soot \\
\hline 0.32 & 53.44 & 8.48 & 41.51 & 6.09 & 1 & 1218 & 0.779 \\
\hline
\end{tabular}

The reduction of the analyzed emissions is a quite delicate problem because the nitrogen oxides emission could not be succeeded without the increase of the soot emission. Analyzing the basic undivided injection cycle it clearly appears that the main problem is that of the NOx. Therefore, some injection configurations could be tested so that the peak firing pressure could eventually decrease with less penalties on the engine efficiency. 
For a second proposed engine regime, the injected fuel is divided into a $20 \%$ injection pilot corresponding to an advance of $8 \mathrm{deg} \mathrm{CA}$ and the rest of the injected fuel with an advance of 2 deg CA (see Fig. 7).

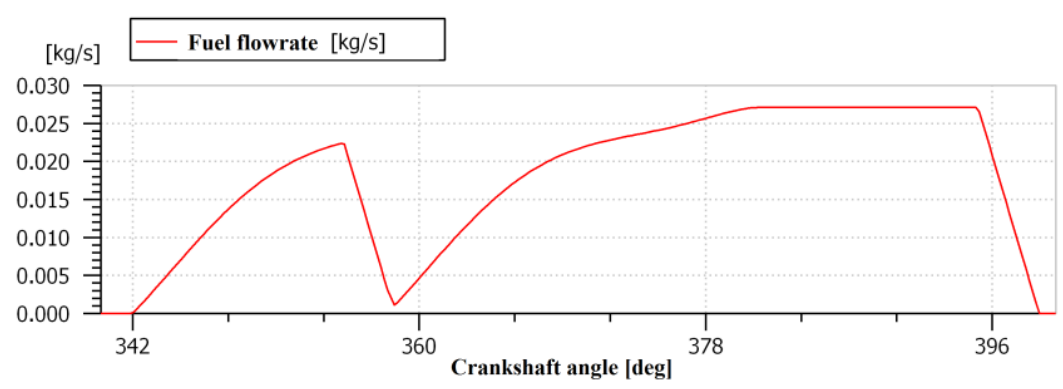

Fig. 7. The injection characteristic for regime no.2

The main injection phase starts approximately when the pilot injection ends and the ending point for the entire injection period is at about $400 \mathrm{deg}$. The engine performances applying this injection case are low, the rated power per cylinder decreasing from $30.3 \mathrm{~kW}$ down to $26.6 \mathrm{~kW}$. The peak firing pressure reaches only 102 bar and the combustion process is expanding until $410 \mathrm{deg}$, as shown in Fig. 8.

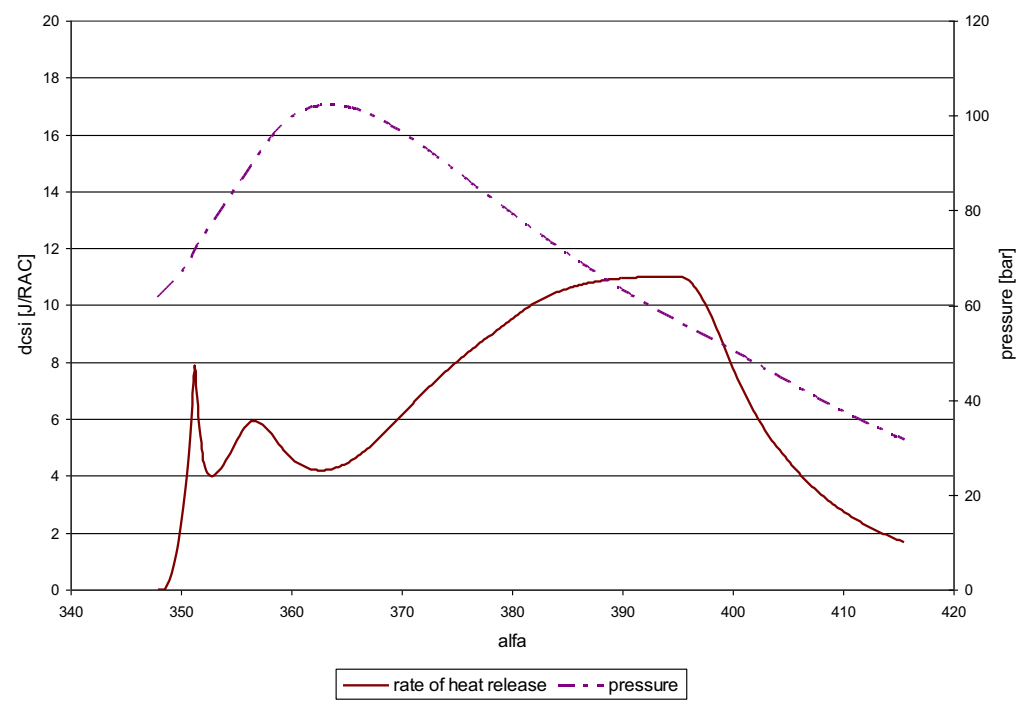

Fig. 8. Cycle characteristics for regime no. 2

In these conditions, the calculated emissions significantly drop, as listed in Table 3:

Table 3 Equation's 2 and 3 values for regime no. 2

\begin{tabular}{|c|c|c|c|c|c|c|c|}
\hline $\mathrm{ZV}$ & $\alpha_{1}$ & $(\mathrm{dp} / \mathrm{d} \varphi)_{\max }$ & $\alpha_{2}$ & $\mathrm{O}_{2}$ & $\mathrm{~m}_{\text {air }} / \mathrm{m}_{\text {fresh charge }}$ & $\mathrm{NO}_{\mathrm{x}}$ & Soot \\
\hline 0.32 & 13.53 & 5.08 & 27.65 & 6.09 & 1 & 172 & 0.120 \\
\hline
\end{tabular}

Maintaining the ratio between the pilot and the main injection fractions $(20 \%$ for the pilot amount and $80 \%$ for the rest), in case of testing a third regime (Regime no.3) the 
advance has been augmented in order to get higher the engine efficiency. Fig. 9 shows the new adopted injection characteristic.

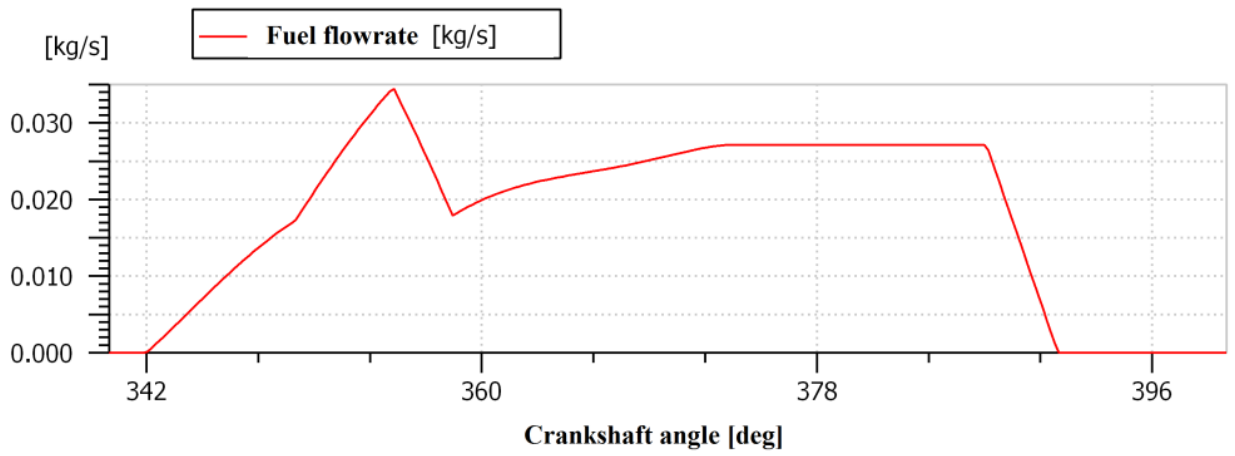

Fig. 9.The injection characteristic for regime no.2

The pilot injection has an advance of $18 \mathrm{deg} \mathrm{CA}$ and the main injection phase occurs with an advance of $10 \mathrm{deg}$ CA. The obtained power in this situation is $27.8 \mathrm{~kW}$, marking a drop of $6 \%$ comparing to the first regime. In this particular case the peak firing pressure is 117 bar. As for Regime no.2, Fig. 10 shows both variations for the cylinder pressure and for the temperature when analyzing Regime no. 3 and Table 4 presents the values for the calculation terms regarding the emissions.

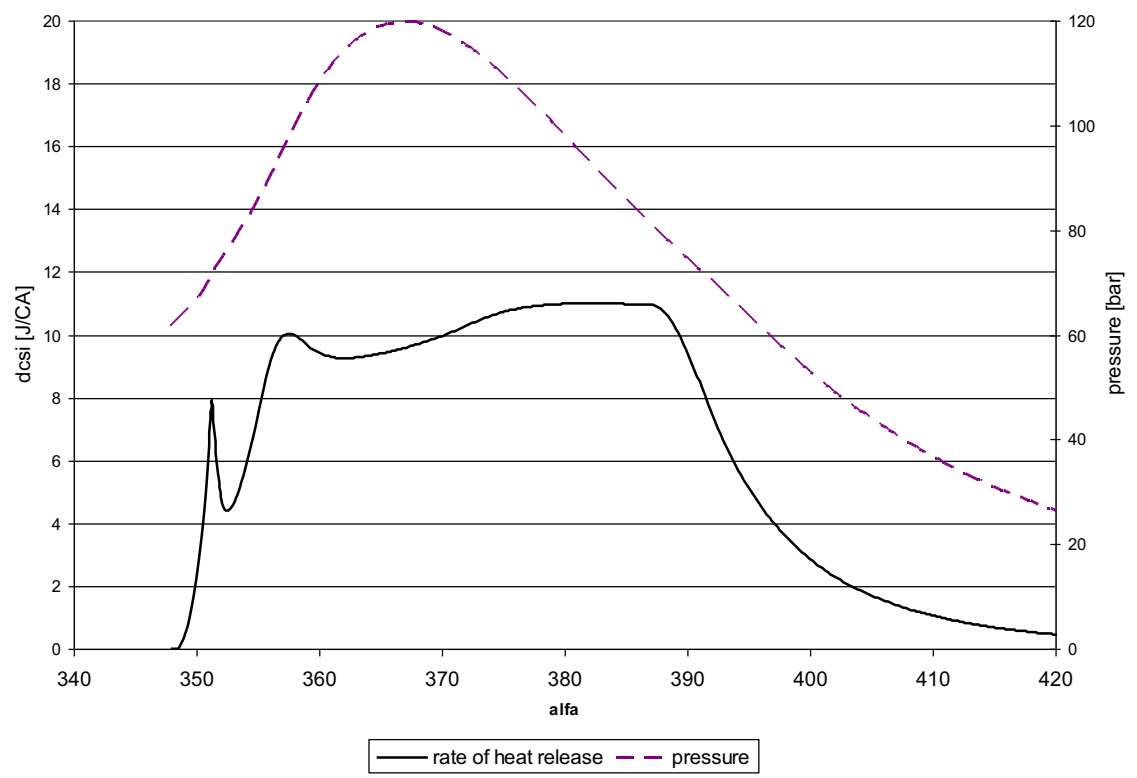

Fig. 10. Cycle characteristics for regime no. 3

Table 4 Equation's 2 and 3 values for regime no. 3

\begin{tabular}{|c|c|c|c|c|c|c|c|}
\hline $\mathrm{ZV}$ & $\alpha_{1}$ & $(\mathrm{dp} / \mathrm{d} \varphi)_{\max }$ & $\alpha_{2}$ & $\mathrm{O}_{2}$ & $\mathrm{~m}_{\text {air }} / \mathrm{m}_{\text {fresh charge }}$ & $\mathrm{NO}_{\mathrm{x}}$ & Soot \\
\hline 0.32 & 18.33 & 5.08 & 26.95 & 6.09 & 1 & 301 & 0.228 \\
\hline
\end{tabular}




\section{Conclusions}

Establishing the mechanism of the emissions formation following Diesel engine in-cylinder processes is very complex according to the chemical reactions and their kinetics. Therefore, this calculation is highly complicate and relatively inaccurate.

This paper combined two methodologies: first, the calculation of an engine cycle using the AMESIM soft procedures and secondary, the evaluation of the engine emissions using an empiric expression in order to track the most common values found in the experimental research data basis.

The proposed method can define a heat release characteristics, which can combine a good yield with relatively low pollutant emissions. These data, coupled with models of gas after-treatment systems, provides solutions for framing the analyzed engine in pollution norms.

This work could lead to an acceptable approximation of soot and $\mathrm{NO}_{\mathrm{x}}$ formation trends when using different operating parameters of the fueling injection process. It opens also the path of research for the autoignition behavior when using different kinds of fuels, such as M, E fuels categories or Diesel-Biodiesel blends.

\section{References}

1. G.S. Hebbar, Int. Jour. of Mech. Eng. and Rob. Res., 3(4), 471 (2014)

2. N.Raeie, S.Emani, O.K. Sadaghiyani, Elsevier Prop.Pow. Res.,3(2), 59 (2014)

3. M.Fiebig, A.Wiartalla, B.Holderbaum, S.Kiesow, J. of Occup. Med. and Tox., 9(6) (2014)

4. S.Prassad, J.Gonsalvis, V.S.Vijay, Elsevier En. and Power, 5(1A), 28 (2015)

5. R.Chiriac, A.Racovitza, P.Podevin, G.Descombes, Elsevier Int. J. of H Energy, 40, 15856 (2015)

6. A.Atmanli, Elsevier Fuel, 176, 209 (2016)

7. J.H.Zhou, C.S.Cheng, C.W.Leung, Elsevier Int. J. of H Energy, 39, 4611 (2014)

8. J.Hussein, K.Palaniradja, N.Alagumurth, R.Manimaran, Alexandria Eng. J., 51 (2012)

9. D. De Serio, A. De Oliveira and J. R. Sodré J of Phys, 745 (2016)

10. ***Emission Standards» European Union» Cars and Light Trucks. DieselNet. January (2015)

11. ***Regulation (EC) No 715/2007. 2007-06-20, 5, Retrieved 2015-10-29

12. J.O'Connor, M.Musculus, SAE Paper 2013-01-0917 (2013)

13. S.Emani, S.Jafarmadar, Elsevier Prop. and Power Research, 2(2), 162 (2013)

14. ***AMESIM IFP Engine Library Rev.14

15. C. Barba, C. Burkhardt, K. Boulouchos, M. Bargente, SAE Paper, 2000-01-2933 (2000)

16. Wenzel, S.,P., Modellierung der Russ und NO Emissionen des Dieselmotors, (Dissertation zur Erlangung des akademischen Grades Doktoringenieur, Magdeburg Universitat, 2006) 